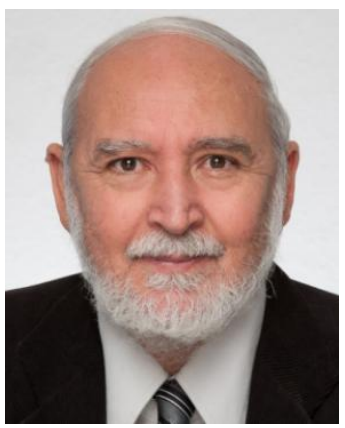

\title{
Energy Mix between Renewable Energy and Nuclear Energy
}

\author{
Prof. Yousri AbuSahdy
}

Energy is the backbone of any development in any State. Renewable Energy (wind, solar and biomass) appears currently as a major strategic energy source for a sustainable development particularly for developing or under developing societies. Use of renewable Energy will challenge major technological changes, by achieving energy production and saving. In particular by replacing fossil fuel, a significant cut of environmental impact and green house gas emission (GHG) could be achieved. In addition Renewable Energy could offer a sustainable development for different societies particularly those in rural area (e.g. desert or isolated islands). The significant technical renewable energy tool developments in developed States could be much easier to be transferred to or copied in developing States .

Due to the lack of continuity of energy production throughout the entire days for solar and wind resources, it would either need an important increase in their cost to save energy from the hours it works to use it during the dead production period, or to use a base-load other energy source. One of the best clean and relatively sustainable is the nuclear energy. The use of energy mix between renewable energy and nuclear energy could offer the best energy strategy for a developing State like Egypt.

The issue of a Journal for renewable energy and sustainable development from the Arab Academy for Science and Technology and Maritime Transport in Alexandria is an important step to address many scientific and technical researches and technical applications in the field and could offer an important reference to national and international affiliations and academic researches. I wish all success to the new Journal in its important field.

\begin{abstract}
About Prof. Yousri AbuSahdy
Prof. Yousri AbuSahdy was awarded his BSc, MSC and PhD in Nuclear Engineering from Alexandria University and France. He was former head of the Nuclear Engineering Department (NED), Alexandria University till 1982.

Prof. AbuShady is an international expert in the field of energy, nuclear energy and designing reactors, in particular. He is also a senior inspector at the International Atomic Energy Agency (IAEA) and former head of its Safeguards Operation Section.

Prof. AbuSahdy assumed duty at IAEA since 1984 till 2009 (for 25 years) during which he was assigned several tasks, held various positions and took part in inspection of hundreds of nuclear facilities in more than 40 countries.

Prof. AbuSahdy was awarded several honorary rewards and certificates of merit, atop of which is the Nobel Peace Prize in 2005 jointly awarded with the IAEA, as well as the International IAEA Distinguished Award for Excellence in Work in 2003 in addition to Alexandria University Encouragement Award in 1981. He also chaired and took part in various international and local scientific conferences and seminars, has a multiplicity of scientific research papers, publications, references and a number of books and articles. Furthermore, he was able to design and manufacture the first prototype of an Egyptian nuclear reactor in collaboration with ten BSc students as their graduation project at the Nuclear Energy Department, Alexandria University in 2012-2013 supported by an Egyptian national factory.
\end{abstract}

Now, he is a member of the Egyptian Council for Foreign Affairs (ACFA), member of PUGWASH International Association that is countering nuclear weapons. Recently, he is a visiting professor at a number of Egyptian universities. 